\title{
ArcheoSciences
}

Revue d'archéométrie

33 (suppl.) | 2009

Mémoire du sol, espace des hommes

\section{Geophysical investigations on Por-Bajin island, Tuva (Russia)}

\author{
I. A. Arzhantseva, M. A. Andreyev, S. A. Akulenko, M. J. Kats and I. N.
} Modin

\section{(2) OpenEdition}

12 Journals

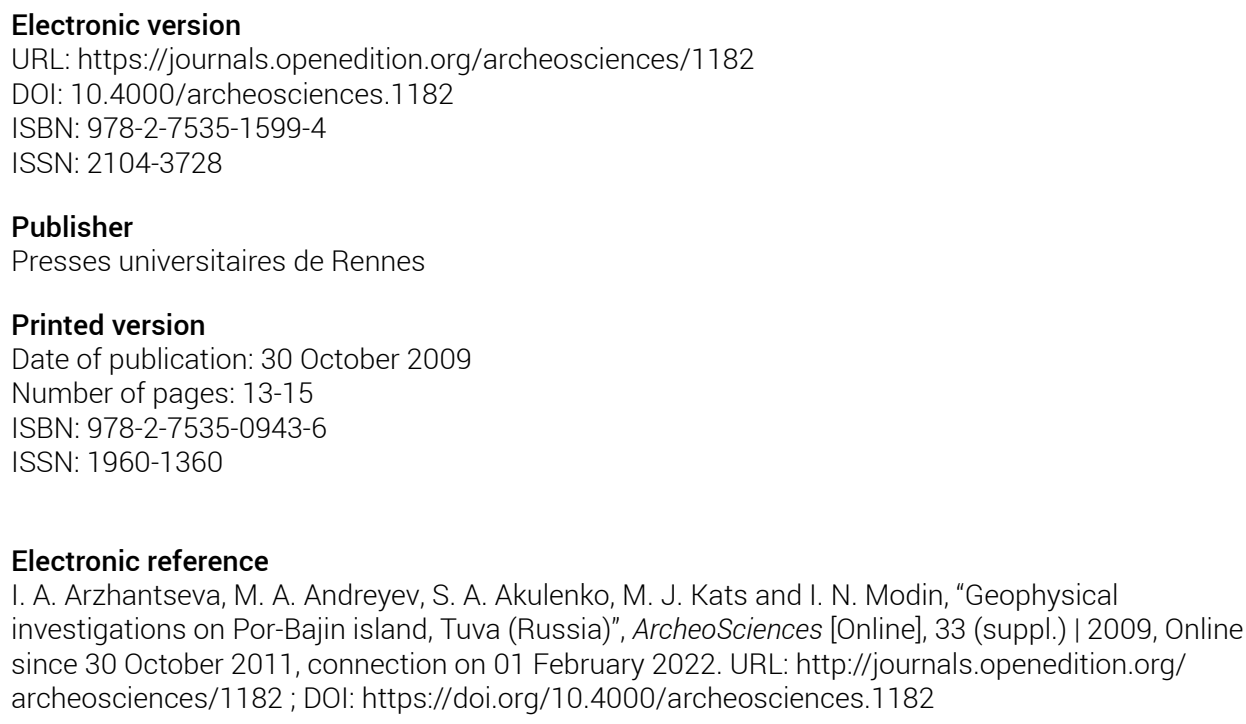




\title{
Geophysical investigations on Por-Bajin island, Tuva (Russia)
}

\author{
I. A. Arzhantseva *, M. A. Andreev**, S. A. Akulenko**, \\ M. J. KaTs ${ }^{* * *}$ and I. N. Modin ${ }^{* *}$
}

Key words: Fortress Por-Bajin, Geophysical investigation, Destructive earthquakes, Permafrost, Fire.

In 2007-2008, the cultural fund «Fortress Por-Bajin » undertook extensive archaeological excavations on the $8^{\text {th }} / 9^{\text {th }}$ century AD monument of Por-Bajin. By the end of the summer season 2008, the total excavated area was about 2 hectares. Some 1000 people took part in this project: archaeologists, architects, soil scientists, geomorphologists and other specialists. Considering the extreme remoteness of the site, the fund developed its own infrastructure for transport, accommodation and safety of this large number of participants. More than 500 students from five Russian universities volunteered to help the archaeologists on site. In the summer of 2008, students and teachers from three foreign universities (Great Britain, Switzerland and Bulgaria) took part in the excavation. At the end of July and the beginning of August 2008, an international fieldwork seminar was organized at the site which attracted a large number of delegates from all over the world.

Even after this extensive and detailed exploration of the site, scholars and scientists do not yet fully understand the purpose of building such a big enclosure in the middle of Lake Tere-Khol (Wainstein, 1964), high in the mountains of Tuva and far from major towns and roads. Several possibilities were debated by the specialists: Por-Bajin may have been the summer residence of the Uighur kaghan, a religious centre, a fortress, or a key-town marking the tomb of the kaghan or his wife. Practically all historians and archaeologists involved agree that the site was not in use for long, perhaps for only about 50 years, and was probably occupied for only brief periods of time. The site was abandoned after a conflagration ample traces of which have been found during the excavations. The destruction of the clay walls has been the result of major earthquakes and deformations by permafrost which underlies virtually the entire island. Variations over time of the water level of the lake have affected the link to the lake shore and turned the peninsula into an island and vice versa at various times of its history. Geophysical research on the site included a survey of the general preservation of the monument, and the search for archaeological features and for the possible burial place of the ruler of Por-Bajin.

Geophysical work (Khmelevskoy, 2007) included the following kinds of geophysical measurements:

- magnetic investigation in the interior of Por-Bajin island on a grid of profiles with distances of $1 \mathrm{~m}$ between them, done with gradient meters POS-2 and G-858 (Geometrics);

\footnotetext{
* Institute of Etnology, Russian Academy of Sciences. (arzhantseva@rambler.ru)

** Faculty of Geology, Moscow State University. (sv-ak@yandex.ru)

*** JSC « Geotechnology».
} 
- seismic prospecting in a variation of the method of refracted waves and the method of common deep point (Logis, Zhukovsky, Russia),

- continuous seismo-acoustic profiling (produced by Seismometry Department, Moscow State University);

- electric resistivity tomography with instruments from ERA (St. Petersburg), and special equipment developed by Geophysics Department, Moscow State University;

- vertical electric soundings by means of three-electrode Schlumberger array with fixed electrode B, and rectangle array method with two orthogonal polarization of the electric field.

- continuous aqua-electric sounding with IMVP-8 instrument and ASTRA alternator (from the firm Northwest, Russia);

- GPR apparatus Zond-12c with a central frequency of $300 \mathrm{MHz}$.

Magnetic survey results have shown that there were no ancient hearths on the island suggesting that Por-Bajin was possibly the summer residence of the Kaghan. Another result from magnetic survey work is the discovery of two big anomalies along a courtyard near the palace. During excavation, the anomalies turned out to correspond to heaps of roof tiles from galleries which had collapsed during a catastrophic fire of. The route around the outside perimeter of the enclosure has shown that there is an intensive anomaly of the magnetic field east of the gate. In 2008, archaeological fieldwork demonstrated that the gate had been destroyed by fire.

Finding objects which have sunk into the lake is a very difficult task. We suggest that there was a gradual non-uniform subsidence which led to the complete destruction of clay constructions in the shore areas.

Seismic research was confined mainly to land areas around the lake. Around the camp, background measurements were carried out which allowed us to establish the general rules. By way of contrast, the method of reflected waves produces velocities of cross-waves of less than $1000 \mathrm{~m} / \mathrm{s}$. It specifies vertical anisotropy in a layered section. Considering that the geological section consists of sandy-argillaceous subsoil, it is possible to assume that the frozen soil in such ground may have characteristic lenses, i.e. thin layers of ice, in sandy layers (with high velocity and resistivity) and in thawed, warm clay layers (with low velocity and resistivity).

Square mapping by the method of refracted waves was carried out in one of the courtyard. The method has shown that the high-velocity boundary of the frozen soil is located at depths from 1.5 to $3.5 \mathrm{~m}$.

Seismo-acoustic research at a frequency of $1000 \mathrm{~Hz}$ was carried out on the lake water table along the bridges which link the camp and the islands. It produced information about the geological section to a depth of $15 \mathrm{~m}$. On the east side of the island, at a depth of 2 to $5 \mathrm{~m}$, we found small diffracting objects that may be fragments of the island or artificial constructions.

GPR was applied on several profiles with a total length of $500 \mathrm{~m}$. Most of the results have fixed, clear reflecting boundary at the surface of frozen soil (Fig. 1).

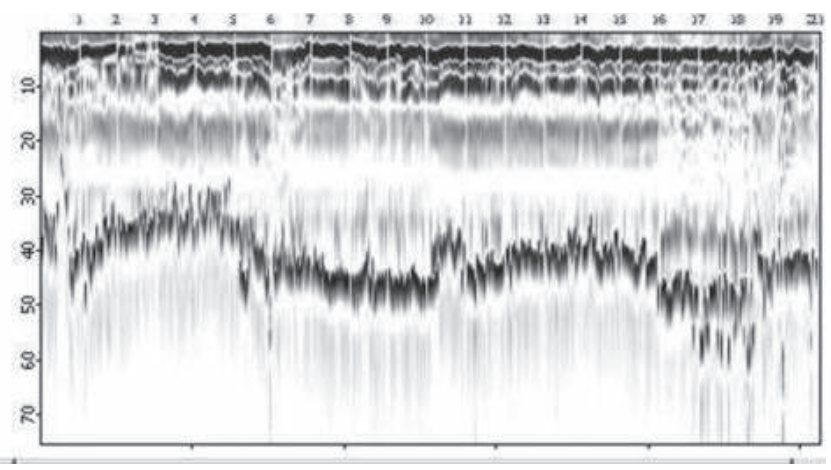

Figure 1 (see color plate): GPR shooting on the island of PorBajin. The lower boundary is the reflection from the top of frozen soil around 40-50 ns (at a depth of 1.5-2 m).

VES has shown that there is permafrost under a thin thawed layer on the land round the lake, and on the islands. The frozen soil has a difficult structure, and the upper boundary of the frozen soil varies from 1.5 to $3.5 \mathrm{~m}$ depending on conditions. Frozen eaves were noted along the island beach and the lake. Usual electric sounding was carried out on the water area of the lake along the bridges. The results show that the southeast part of the lake has a three-layer structure. Under the water, there is a thin layer of consolidated silt. The second layer consists of several meters of clay while the third layer is sand at a depth of 8 to $10 \mathrm{~m}$. Under the sand, there is a fourth clay layer of great thickness.

Electric resistivity tomography (Bobachev et al., 1996) has shown that from the point of view of safety the condition of archaeological features depends on the permafrost (Fig. 2). The destruction of walls happens under warming action which deforms the soil surface and leads to fractures. Using ERT, we identified a bipolar structure of the internal walls which are exposed to intensive warming by the sun on the southern face, and collect moisture on the northern face.

A rectangular array was used in the interior of the enclosure. The distance from A to B was $120 \mathrm{~m}$. Each area was worked at two polarizations of the electric field. This highlighted features of different conductivity and with different directions, suggesting the following conclusions. The centre 


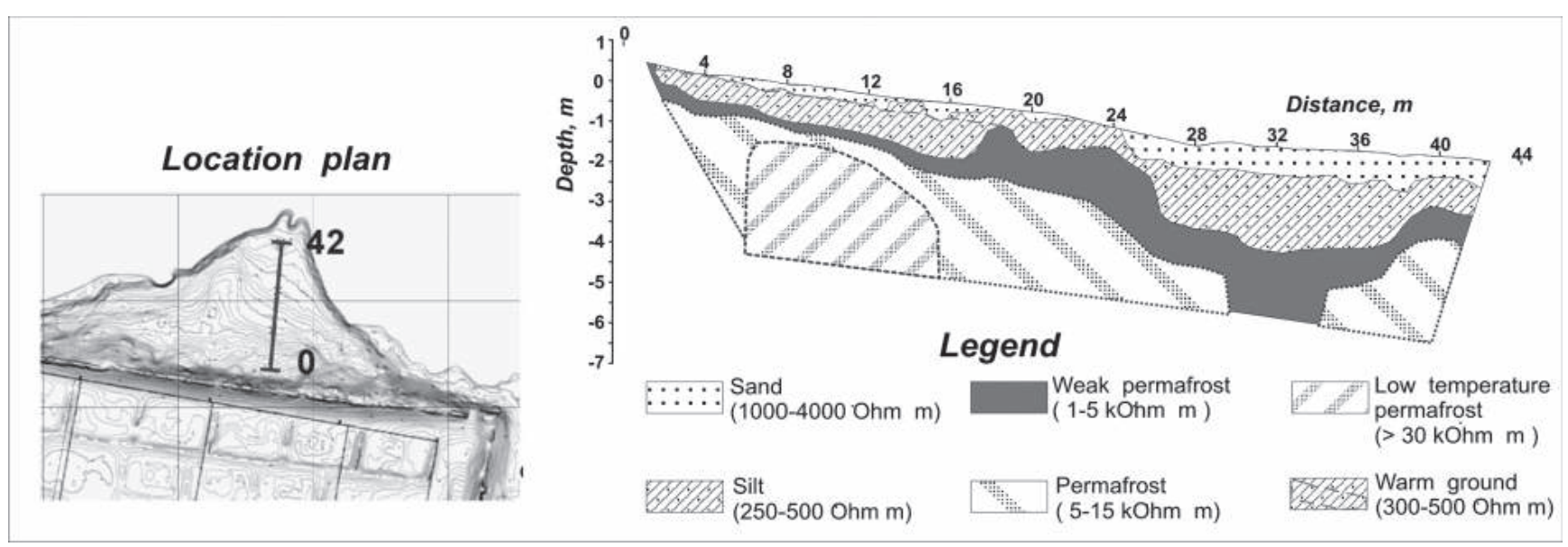

Figure 2: Results of Electric Resistivity Tomography on the northern profile.

of island around palace complex have the lowest permafrost temperatures, shown by the maximum electric resistivity of the soil. The island is of rectangular shape which means that the corner towers are projecting considerably towards the lake. As a result, they have undergone maximum warming. On seams which cut island corners, there is a lowering of the soil surface, possibly as a result of destructive earthquakes. Different parts of the "fortress " site have suffered to different degrees from permafrost degradation and earthquakes.

Continuous electric soundings made a palaeogeographical reconstruction possible. It is reasonably certain that at the time when the «fortress » of Por-Bajin was built, open water existed only in the western part of the present-day extent of
Lake Tere-Khol', to the west of the island of Por-Bajin. The enclosure was therefore built on the tip of a large peninsula. At that time, there was also a lake area in the northeast part of Tere-Khol', and this was linked to the southwestern water area by a narrow strait.

\section{References}

Bobachev, A. A., Modin, I. N., Pervago, E. V., Shevnin, V. A, 1996. Multielectrode electric sounding in non-horizontallayered environments, The review. Geo-informmark, 2.

KHMElevsKoy, V. K., (dir.). 2007. Geophysics. Moscow, KDU.

Wainstein, S. I., 1964. Ancient Por-Bajin. Sovetskaya etnografiya, 6: $103-114$. 